\title{
Differential Activation of Ammonium Transporters During the Accumulation of Ammonia by Colletotrichum gloeosporioides and Its Effect on Appressoria Formation and Pathogenicity
}

\author{
Chen Shnaiderman,, ${ }^{1,2}$ Itay Miyara, ${ }^{1}$ Ilana Kobiler, ${ }^{1}$ Amir Sherman, ${ }^{3}$ and Dov Prusky ${ }^{1}$ \\ ${ }^{1}$ Department of Postharvest Science of Fresh Produce, ARO, Bet Dagan, Israel; ${ }^{2}$ The Robert H. Smith Faculty of Agriculture, \\ Food and Environment, the Hebrew University of Jerusalem, Rehovot, Israel; ${ }^{3}$ Genomic Unit, Plant Sciences Institute, ARO, \\ Bet Dagan, Israel
}

Submitted 9 July 2012. Accepted 30 October 2012.

\begin{abstract}
Ammonium secreted by the post-harvest pathogen Colletotrichum gloeosporioides during host colonization accumulates in the host environment due to enhanced fungal nitrogen metabolism. Two types of ammonium transporterencoding genes, $A M E T$ and $M E P$, are expressed during pathogenicity. Gene disruption of $A M E T$, a gene modulating ammonia secretion, showed twofold reduced ammonia secretion and $45 \%$ less colonization on avocado fruit, suggesting a contribution to pathogenicity. $M E P B$, a gene modulating ammonium transport, is expressed by $C$. gloeosporioides during pathogenicity and starvation conditions in culture. Gene disruption of $M E P B$, the most highly expressed gene of the $M E P$ family, resulted in twofold overexpression of $M E P A$ and $M E P C$ but reduced colonization, suggesting $M E P B$ expression's contribution to pathogenicity. Analysis of internal and external ammonia accumulation by $\Delta m e p B$ strains in mycelia and germinated spores showed rapid uptake and accumulation, and reduced secretion of ammonia in the mutant versus wild-type (WT) strains. Ammonia uptake by the WT germinating spores but not by the $\triangle m e p B$ strain with compromised ammonium transport activated cAMP and transcription of $P K A$ subunits $P K A R$ and $P K A 2$. $\triangle m e p B$ mutants showed $75 \%$ less appressorium formation and colonization than the WT, which was partially restored by $10 \mathrm{mM}$ exogenous ammonia. Thus, whereas both $A M E T$ and $M E P B$ genes modulate ammonia secretion, only $M E P B$ contributes to ammonia accumulation by mycelia and germinating spores that activate the cAMP pathways, inducing the morphogenetic processes contributing to $C$. gloeosporioides pathogenicity.
\end{abstract}

$\mathrm{pH}$ modulation by pathogenic fungi of the host environment has been shown to be a significant factor for modulation of pathogenicity in several fungi via either alkalinization or acidification as a result of ammonia or organic acid secretion, respectively (Prusky and Yakoby 2003). The extent of the $\mathrm{pH}$

Corresponding author: D. Prusky; E-mail: dovprusk@agri.gov.il; Telephone: +972-3-9683610; Fax: +972-3-9683622.

* The $\boldsymbol{e}$-Xtra logo stands for "electronic extra" and indicates that Figure 8 appears in color online.

(C) 2013 The American Phytopathological Society change in the plant tissue depends on host buffer capacity and initial pH (Alkan et al. 2008; Kramer-Haimovich et al. 2006; Prusky et al. 2001). The pathogen's ability to alter pH locally was initially described for Sclerotinia sclerotiorum but similar findings were then extended to other pathogens, such as Colletotrichum spp., Alternaria alternata, Botrytis cinerea, Penicillium expansum, P. digitatum, P. italicum, Phomopsis mangiferae, and Fusarium oxysporum (Barad et al. 2012; Davidzon et al. 2010; Eshel et al. 2002; Manteau et al. 2003; Miyara et al. 2010, 2012; Prusky et al. 2001, 2004; Rollins and Dickman 2001). The wide number of species modulating host $\mathrm{pH}$ stresses the importance of this mechanism during fungal colonization (Miyara et al. 2012).

Colletotrichum gloeosporioides (Penz.) Penz. \& Sacc. is a necrotrophic ascomycete fungus that secretes ammonia under inductive environmental conditions during fruit colonization as a mechanism for the induction of alkalinization during pathogenicity (Diéguez-Uribeondo et al. 2008; O'Connell et al. in press; Prusky and Yakoby 2003). Ammonium accumulation has been detected in association with host alkalinization and pathogenicity of many Colletotrichum spp., including C. gloeosporioides, C. acutatum, C. higginsianum, C. graminicola, and $C$. coccodes (Alkan et al. 2008; Diéguez-Uribeondo et al. 2008; Miyara et al. 2010; O'Connell et al. 2012), A. alternata (Eshel et al. 2002) and F. oxysporum (Miyara et al. 2012). The roles suggested for the ammonia accumulated during Colletotrichum colonization include i) activation of fungal pathogenicity factors such as pectate lyase (Prusky and Yakoby 2003), ii) induction of host-cell death and host response during necrotrophic development (Alkan et al. 2008, 2009, 2012), and iii) induction of appressorium formation during host penetration (Miyara et al. 2010).

Macroarrays carrying $C$. gloeosporioides cDNA expressed during the alkalinization process have been used to monitor the genes expressed during ammonia metabolism (Miyara et al. 2010). Genes expressed during early stages of alkalinization at $\mathrm{pH} 4.0$ include $G D H 2$ encoding $\mathrm{NAD}^{+}$-specific glutamate dehydrogenase and $A M E T$ encoding for a protein with homology to an ammonia transporter, whereas $M E P B, G L T$, and $G S 1$, encoding for protein sequence homology to methyl ammonia permease, glutamate transporter, and glutamine synthethase, respectively, are induced at increasing $\mathrm{pH}$ close to 7.0 (Miyara et al. 2010). The importance of ammonia in pathogenicity has been studied via modulation of ammonia production. Reduction of ammonia production by $n^{-} t^{-}$areA or $\Delta g d h$ 
mutant strains elicits a reduction in host colonization (Alkan et al. 2009; Miyara et al. 2010). Some mutants, such as the $\Delta g d h 2$ strains of $C$. gloeosporioides and Magnaporthe oryzae and the $\triangle$ mepB of $C$. gloeosporioides, show reduced appressorium formation as well (Miyara et al. 2010, 2012; Oh et al. 2008). Miyara and associates (2012) analyzed a $\triangle m e p B$ mutant strain for the contribution of the $M E P B$ gene to ammonia uptake and accumulation by $C$. gloeosporioides in comparison with the GLT gene modulating glutamate transport; both mutants inhibited appressoria formation and pathogenicity.

In the present study, we compared the ammonia uptake or secretion by two groups of genes encoding for ammonia transporters, $A M E T$ and $M E P A, M E P B$, and $M E P C$, and analyzed the effect of gene knockout on ammonia accumulation, induction of appressorium formation, and pathogenicity of $C$. gloeosporioides. Functional analysis of AMET mutants suggested that this gene encodes a protein with minimal effects on ammonia uptake and accumulation in the hyphae. AMET contributes to the pathogenicity of $C$. gloeosporioides by its effect on ammonia secretion. Functional analysis of the $M E P B$ mutant of $C$. gloeosporioides indicated that, of the $M E P$ genes encoding for a methylammonium permease, $M E P B$ showed the main regulation of the influx, efflux, and accumulation of ammonia in the fungal hyphae. Because previous data had indicated the importance of cAMP-PKA pathways as signaling factors for the induction of appressorium formation (Gold et al. 1997; Kronstad 1997; Lee et al. 2003; Takano et al. 2000; Taylor et al. 1990), we used the $\triangle m e p B$ mutant strain to show that processes involving ammonia uptake and cAMP activity occur concurrently and enhanced ammonia accumulation activated PKA subunits PKA2 and $P K A R$. These results suggest that the balance between uptake and secretion of ammonia by germinating spores may induce signaling pathways that enhance appressorium formation, com- pared with the developing mycelia where the secretion of ammonia and host alkalinization contribute mainly to necrotrophic colonization by $C$. gloeosporioides.

\section{RESULTS}

Functional analysis of $C$. gloeosporioides AMET: Effect on ammonia export and pathogenicity.

The sequences of the Amet proteins in C. gloeosporioides were analyzed in the conserved domains database of the National Center for Biotechnology Information and found to belong to the GPR1/FUN34/yaaH family, with an $e$ value of $9.25 \mathrm{e}^{-34}$. The single copy of AMET found in C. gloeosporioides preliminary genome sequence (D. Prusky, unpublished) showed 90\% homology to FUN34 of Glomerella graminicola and FUN34 of $C$. higginsianum. Promoter analysis of the 1,000-bp region upstream of the $5^{\prime}$ untranslated region (UTR) of the $A M E T$ sequence revealed 13 putative CREA binding motifs, one $A R E A$ binding motif that might modulate ammonia export (Monahan et al. 2006), and no putative $P A C C$ binding motifs.

To assess the function of AMET in C. gloeosporioides, gene knockout was performed to generate $\Delta$ amet strains (Fig. 1A) in which the intact $A M E T$ was replaced with an AMET5'-HygAMET3' cassette, as described by Shafran and associates (2008). Deletion of the gene was confirmed by polymerase chain reaction (PCR) (Fig. 1B). Expression of AMET was detected by quantitative reverse-transcriptase PCR (Fig. 1C) in the wild-type (WT) progenitor strain $\mathrm{Cg}-14$ and ectopic en $_{4}$ strains, whereas minimal levels of expression were detected in

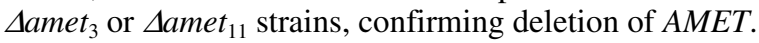

Characterization of the AMET mutants in solid media showed that none of them are affected in fungal growth in vitro or in spore germination. To characterize the mutants in

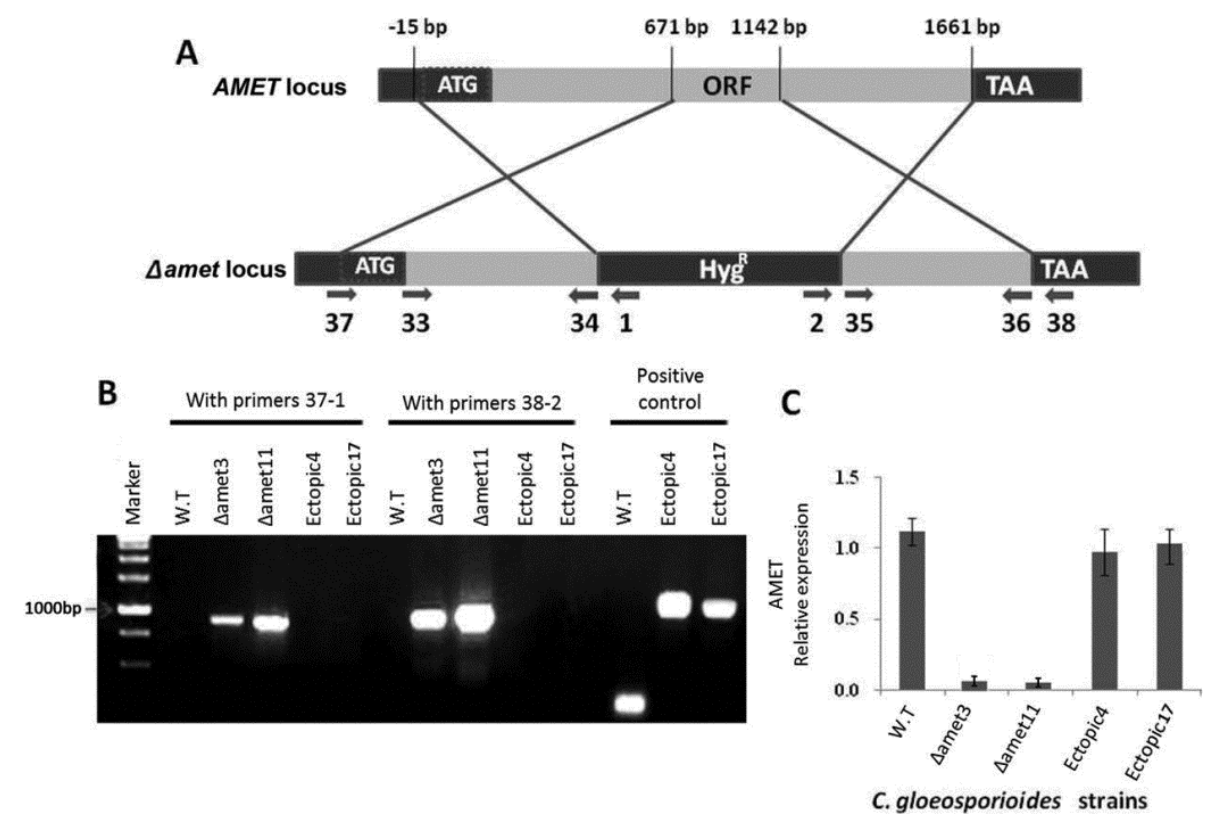

Fig. 1. Development of $A M E T$ mutant strains. A double crossing-over homologous recombination event resulting in replacement of the original $A M E T$ sequence with the AMET5'-Hyg-AMET3' cassette was carried out (Miyara et al. 2012). A, Scheme depicting gene disruption by homologous recombination. Primer pairs 13-14 were used for the $5^{\prime}$ end and 15-16 for the $3^{\prime}$ end. B, Polymerase chain reaction (PCR) analysis of the wild-type (WT) strain, ectopic colony (Ectopic ${ }_{4}$ and Ectopic $_{17}$ ), and independent AMET-disruption colonies ( $\triangle$ amet $)$. Primer 17 flanking a position upstream of the AMET2:HYG3 region and reverse primer 11 located on the hygromycin cassette were used to identify positive AMET gene replacement at the $5^{\prime}$ locus. Primer 12 from the hygromycin cassette and primer 18 flanking the AMET:HYG3 region were used to identify AMET gene replacement at the $3^{\prime}$ locus. $18 S$ gene primers 1 and 2 were used for WT DNA quality control. Primers 11 and 13 were used as a positive control for the ectopic strains, to confirm random integration of the AMET:HYG3 cassette. C, Expression of AMET in the WT strain (relative expression to value 1) compared with the ectopic-integration control and the $\triangle a m e t$ strains, as detected by quantitative reverse-transcriptase (qRT-)PCR. Cultures were initially grown in $\mathrm{M}_{3} \mathrm{~S}$-rich medium and were then transferred to broth minimal medium without nitrogen source for $5 \mathrm{~h}$ prior to RNA extraction. Relative expression values obtained by qRT-PCR are normalized against $18 S$ rRNA. Average \pm standard deviation from three replications of one treatment is presented. 
liquid media, 3-day hyphal mats of the Aamet isolates were transferred from the initial $\mathrm{M}_{3} \mathrm{~S}$ medium to ammonia-inducing

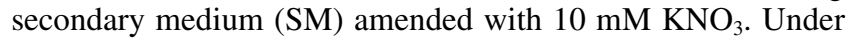
these conditions, the concentration of ammonia accumulated in the growth culture was reduced by almost $50 \%$ in all the mutant strains (from 2.8 to $1.35 \mathrm{mM}$ ammonia per gram dry weight of fungal mycelium [hereafter $\mathrm{mM} \mathrm{g}^{-1}$ ]) $24 \mathrm{~h}$ postinoculation of SM. At the same time, the $\mathrm{pH}$ of the medium increased from 4.0 to 6.0 for the WT and ectopic strains, whereas it only increased to 5.5 for the $\Delta$ amet strains (Fig. 2), suggesting that $A M E T$ knockout affects the secretion of ammonia from growing fungi. If the $\Delta a m e t$ isolates were transferred from the initial $\mathrm{M}_{3} \mathrm{~S}$ medium to $\mathrm{SM}$ amended with $10 \mathrm{mM}$ $\mathrm{NH}_{4} \mathrm{Cl}$, the average uptake of ammonia from the media increased $6 \mathrm{~h}$ after transfer by $20 \%$ by both $\Delta$ amet $_{11}$ and $\Delta$ amet $_{3}$ strains compared with the WT and ectopic Damet4 strains. However, $3 \mathrm{~h}$ later, no difference in the remaining ammonia in the media between the mutant and the controls was observed, suggesting only a minor capability for the AMET knockout to affect the uptake of ammonia from growing fungi. This was confirmed by the lack of differential accumulation of ammonia inside the hyphae $9 \mathrm{~h}$ after transfer of the Damet and control strains to the $\mathrm{SM}$ amended with $\mathrm{NH}_{4} \mathrm{Cl}$. Pathogenicity assays of $\Delta a m e t_{3}$ and $\Delta_{a m e t}$ strains compared with the WT showed a $42 \%$ reduction in avocado fruit colonization (Fig. 3), indicating the contribution of $A M E T$ to $C$. gloeosporioides colonization. No effect was observed also on the amount of appressoria formed by the damet strains when the germination occurred on avocado fruit pericarp, suggesting that attenuation of fungal colonization on fruit results from the reduced ammonia production.

\section{Expression of $C$. gloeosporioides ammonium permeases $M E P A, M E P B$, and $M E P C$ and their effect on pathogenicity.}

The sequences of the three Mep proteins in C. gloeosporioides were analyzed by PSORT and TMHMM and were found to share 55 to $60 \%$ homology. Protein analysis predicted nine transmembrane-spanning domains (TMD) in $M E P B$ and 11 TMD each in $M E P A$ and $M E P C$. Promoter analysis of the 1,000-bp region upstream of the $5^{\prime}$ UTR of the $M E P B$ sequence revealed 17 putative $C R E A$-binding motifs, seven $A R E A$-binding motifs, and two putative $P A C C$-binding motifs. In the $M E P A$ promoter, $17 C R E A-$, three $A R E A$-, and no $P A C C$-binding motifs were found whereas, in the $M E P C$ sequence, only a single $C R E A$-binding site was found in the promoter region (only 184 bp upstream of the $5^{\prime}$ UTR of $M E P C$ were analyzed).
Growth of C. gloeosporioides in culture under nitrogen starvation (no $\mathrm{N}$ ) at $\mathrm{pH} 4$ or 7 showed that, at both $\mathrm{pH}$ values, the relative expression of $M E P B$ is approximately three to 50 times greater than that of $M E P A$ or $M E P C$ (Fig. 4). Growth of the WT strain in the presence of $10 \mathrm{mM} \mathrm{NH}_{4} \mathrm{Cl}$ severely repressed expression of all MEP genes, regardless of $\mathrm{pH}$ (Fig. 4).

To functionally analyze the effects of $M E P A, M E P B$, and $M E P C$ on the balance between ammonia uptake and secretion by the fungus, the levels of ammonia were quantified in the mycelium and freshly produced spores of C. gloeosporioides. A 3-day hyphal mat of the Colletotrichum isolates was transferred from the initial $\mathrm{M}_{3} \mathrm{~S}$ medium to $\mathrm{SM}$ amended with $\mathrm{NH}_{4} \mathrm{Cl}$ (Fig. $5 \mathrm{~A})$. At $6 \mathrm{~h}$ postinoculation, ammonia concentration in the growth media of the previously developed $\triangle m e p B$ strains (Miyara et al. 2012) declined from 25 to $6 \mathrm{mM} \mathrm{g}^{-1}$, whereas it remained steady in the WT, ectopic, and complemented strains. Then, $3 \mathrm{~h}$ later, the level of ammonia in the media had declined for the WT, ectopic, and complemented strains as well-to 6 $\mathrm{mM} \mathrm{g}^{-1}$ - and the ammonia concentration remaining in the growth media of the $\triangle m e p B$ strains had further decreased to the almost undetectable level of $0.01 \mathrm{mM} \mathrm{g}^{-1}$ (Fig. 5A).

Analysis of ammonia level inside the hyphae showed the opposite behavior (Fig. 6B). Whereas, in the WT, ectopic, and

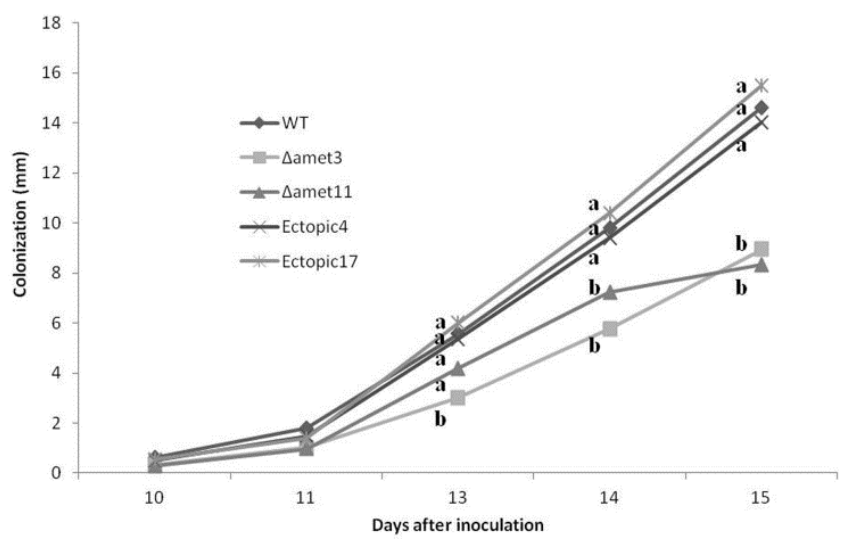

Fig. 3. Pathogenicity assays of Colletotrichum gloeosporioides wild-type (WT), ectopic, and Aamet mutant strains. Decay development of WT and mutant strains after inoculation of the pericarp of freshly harvested 'Fuerte' avocado fruit. Inoculation was carried out by placing spore suspension on the pericarp of unwounded fruit followed by incubation at $25^{\circ} \mathrm{C}$ under high humidity. Average colonized area for 10 infected fruit 10 to 15 days after inoculation is reported. Values within averages marked with different letters at each sampling time differ significantly according to Tukey-Kramer honestly significant difference test at $P \leq 0.05$.

\section{4 hours in secondary media}
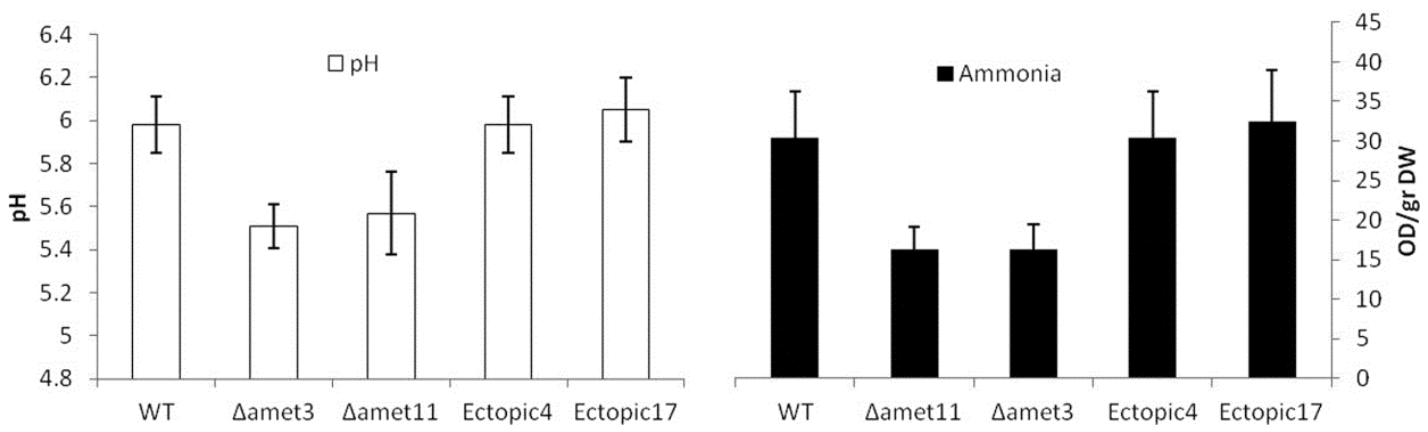

Fig. 2. Ammonia accumulation and pH changes induced in the wild-type (WT) and Aamet Colletotrichum gloeosporioides strains in culture medium. Spores of $C$. gloeosporioides were inoculated in primary medium and 3 days later, transferred to secondary medium amended with 10 mM $\mathrm{KNO}_{3}$, and then analyzed $24 \mathrm{~h}$ postinoculation (hpi). Average \pm standard deviation of three replications of one experiment out of three repeated experiments is presented. Values within averages marked with different letters at each sampling time differ significantly according to Tukey-Kramer honestly significant difference test at $P \leq 0.05$. OD, optical density; DW, dry weight. 
complemented strains, the concentration of ammonia in the mycelium decreased dramatically from 78 to $26 \mathrm{mM} \mathrm{g}^{-1}$ during the first $6 \mathrm{~h}$ postinoculation, in the $\triangle m e p B$ strains, it remained steady (within the range of 60 to $75 \mathrm{mM} \mathrm{g}^{-1}$ ), indicating accumulation of ammonia in these mutants (Fig. 5B). Then, $3 \mathrm{~h}$ later, the level of ammonia in the $\triangle m e p B$ strain had declined to $45 \mathrm{mM} \mathrm{g}^{-1}$ and that in the WT and ectopic strains to approximately $40 \mathrm{mM} \mathrm{g}^{-1}$ (Fig. 5B).

Analysis of the relative expressions of $M E P A,-B$ and $-C$ (Fig. 5D to F) in the WT in the inducing media showed that the initial expression of $M E P B$ is 4.5- and 9.0-fold greater than that of $M E P A$ and $M E P C$, respectively (Fig. $5 \mathrm{D}$ to F). At $6 \mathrm{~h}$ after culture inoculation of $\triangle m e p B$, relative expressions of its $M E P A$ and $M E P C$ were upregulated by three- and 15-fold, respectively, compared with their expression in the WT strain. These results suggest that the increased expression of $M E P C$ does not contribute to the secretion of ammonia and the produced ammonia remains restricted to the fungal mycelia.

Similar results were observed when the expressions of $M E P A, M E P B$, and $M E P C$ were analyzed in inoculated avocado fruit. Highest expression of $M E P B$ was also observed when the mycelia of the WT $C$. gloeosporioides colonized avocado pericarp (Fig. 6A). The relative expression of $M E P B$ in the WT strain in the colonized avocado tissue was 2 and 1.25 times greater than that of $M E P A$ and $M E P C$, respectively (Fig. 6A). When the $\triangle m e p B$ strain was used to inoculate avocado pericarp, the relative expression of $M E P A$ and $M E P C$ by

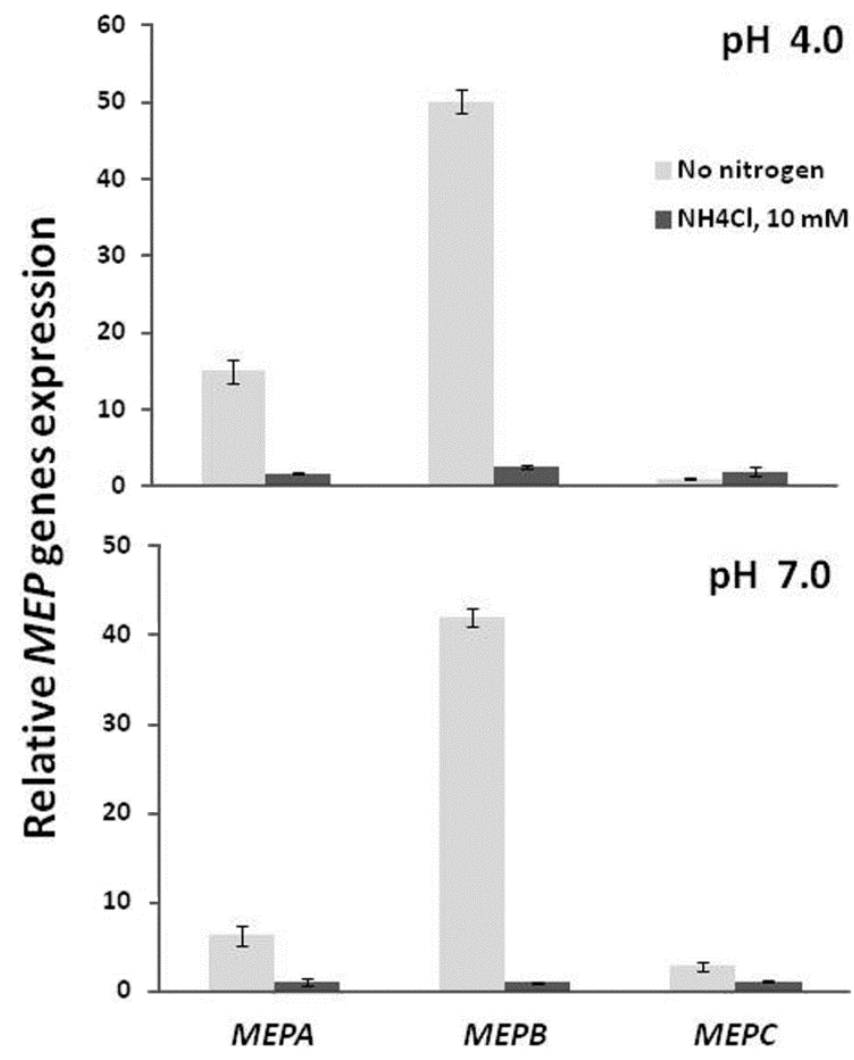

Fig. 4. Expression analysis of $M E P A, M E P B$, and $M E P C$ under $\mathrm{NH}_{4} \mathrm{Cl}$ and $\mathrm{pH}$ growth conditions. Three-day-old mycelium grown in $\mathrm{M}_{3} \mathrm{~S}$ was transferred to secondary medium at $\mathrm{pH} 4.0$ or 7.0 , amended with $10 \mathrm{mM}$ $\mathrm{NH}_{4} \mathrm{Cl}$, or not amended ("No nitrogen" treatment). Samples were taken 9 $\mathrm{h}$ postinoculation for relative expression determination by quantitative reverse-transcriptase polymerase chain reaction. Relative expressions of the different treatments were compared with that of the MEPA in the wildtype (WT) strain, which was given a value of 1 . Values were normalized against $18 \mathrm{~S}$ rRNA. Average \pm standard deviation of relative expression from three technical replications of one treatment is presented. the $\triangle m e p B$ strain was 50 and $40 \%$, respectively, greater than their expression in the WT, paralleling an $87 \%$ reduction in fruit colonization (Fig. 6B) and indicating the importance of $M E P B$ in pathogenesis.

The increased internal ammonia accumulation by the $\triangle m e p B$ strains raised the question of a possible mechanism for detoxification by the pathogen. Stephenson and associates (1997) described a mechanism for ammonia detoxification via the activation of glutamate synthetase (GS). Analysis of $G S$ during fungal growth in inducing media showed two- to fourfold higher relative expression levels during the first $6 \mathrm{~h}$ in the hyphae of the $\Delta m e p B_{12}$ isolate (Fig. 5C), suggesting that the process of glutamate enhancement is induced in the $\Delta m e p B_{12}$ strain.

\section{Reduction of ammonia secretion by germinating spores} inhibited appressorium formation in the $\triangle m e p B$ strains.

Activity of the nitrogen metabolism that modulates ammonia accumulation in germinating spores differed from that in the mycelium (Fig. 5). In germinating spores of the WT strain, continuous secretion of ammonia was observed during the first $9 \mathrm{~h}$ of germination, in contrast to lack of secretion in the $\triangle m e p B$ strains, suggesting that the spores of the mutant strains were impaired in ammonia-secretion capability (Fig. 7A). Analysis of the internal ammonia concentrations showed a buildup from 9 to $42 \mathrm{mM}$ per $10^{6}$ spores in the WT strains in the first $9 \mathrm{~h}$ after initiation of germination (Fig. 7B). In the first $6 \mathrm{~h}$ of germination, the internal ammonia level in the $\triangle m e p B$ strains remained higher, 42 to $43 \mathrm{mM}$ per $10^{6}$ spores (Fig. 7B). The increased accumulation of ammonia led us to search for a possible mechanism of detoxification of ammonia accumulated inside the spore. GS relative expression in the germinating spores of the $\Delta m e p B_{12}$ isolate was fivefold higher than in the WT strain during the first hour of germination, suggesting that accumulation of ammonia (Fig. 7C) activates the enhancement of GS transcript expression levels. Accumulation of high internal levels of ammonia in pre- and post-germinated $\Delta m e p B_{12}$ spores, in contrast to the WT, was easily confirmed by detection of strong fluorescence following treatment with the alkaline fluorescence dye $2^{\prime}, 7^{\prime}$-bis(carboxyethyl)-5(6)-carboxyfluorescein (BCECF) (Fig. 8).

The effect of the external accumulation of ammonia by $C$. gloeosporioides germinating spores on mycelial growth, conidial germination, and appressorium formation was determined by comparing ammonia-secreting strains-the WT and complemented strain - to the nonsecreting strains $\triangle m e p B 3$ and $\triangle m e p B_{12}$. Mycelial growth of $\triangle m e p B 3$ and $\Delta m e p B_{12}$ strains on water or SM amended with $5 \mathrm{mM} \mathrm{NH}_{4} \mathrm{Cl}$ did not affect fungal growth (results not shown) or spore germination compared with the WT, ectopic5, and complemented strains (Table 1). However, germinated $\triangle m e p B$ strain spores showed $75 \%$ inhibition of appressorium formation compared with the WT and ectopic strains (Table 1). Pharmacological complementation of the $\triangle m e p B$ strains by addition of $5 \mathrm{mM}$ volatile $\mathrm{NH}_{4} \mathrm{Cl}$ to germinated spores enhanced the percentage of appressoria formed by $20 \%$ (Table 1). This differential appressorium formation affected overall fungal colonization, as reflected by the diameters of the $\triangle m e p B 3$ and $\triangle m e p B_{12}$ strains' colonies on the pericarp of avocado fruit, which were $78 \%$ smaller than those of the WT 7 days after inoculation: $4 \pm 0.1 \mathrm{~mm} 2$ compared with $18 \pm 0.2 \mathrm{~mm}^{2}$ (Fig. 6B).

Based on early reports describing the impact of the cAMPPKA pathways on appressorium formation (Kojima et al. 2002; Lee and Dean 1993, 1994; Takano et al. 2000; Taylor et al. 1990), we used the non-ammonium-secreting spores of the $\Delta$ терB strains with exogenous ammonia treatment as a 
tool to analyze the mechanism of induction of appressorium formation. Analysis of ammonia secretion of germinating spores of WT and complemented strains treated with exogenous $\mathrm{NH}_{4} \mathrm{Cl}$ showed rapid uptake and time-dependent resecretion of ammonia to the medium (Fig. 9A and C) accompanied by enhanced cAMP activity (Fig. 9D and F), in contrast to the slow release of ammonia and low cAMP activity (Fig. $9 \mathrm{~B}$ and E) in untreated WT spores. Exogenous ammonia treatment of $\triangle m e p B$ spores did not enhance ammonia uptake or induce cAMP activity (Fig. 9B and E), suggesting the importance of ammonia uptake for cAMP activation during spore germination.

To further evaluate the role of ammonia on the PKA pathway of germinated spores, transcript activation of the genes PKAR (encoding the PKA regulatory subunit) (Kamaruddin et al. 2008) and PKA2 (encoding a PKA catalytic subunit) (Liebmann et al. 2004) were compared in the ammonia-secreting WT strain and a nonsecreting strain, $\Delta m e p B_{12}$. Transcript activation in both strains was compared $8 \mathrm{~h}$ after initiation of germination when no ammonia was produced by the $\Delta m e p B_{12}$ strain (Fig. 10). Analysis of the relative expressions of $P K A 2$ and $P K A R$ showed 20- and 30-fold upregulation, respectively, in contrast to inhibited expression in the $\Delta m e p B_{12}$ strain (Fig. 10), suggesting that ammonia uptake may activate the PKA pathway as well.

\section{DISCUSSION}

C. gloeosporioides ammonium transporters.

The Colletotrichum sp. alkalinizes its immediate environment during colonization by secreting large amounts of ammonium ions (Drori et al. 2003; Kramer-Haimovich et al. 2006; O'Connell et al. 2012). The dynamic nature of the system, which involves modulating ammonia export and import, indicates that the secreted ammonia is reassimilated by the ammonium transporters of $C$. gloeosporioides (Miyara et al. 2012). The $C$. gloeosporioides AMET gene encoding for an ammonium transporter showed $90 \%$ homology to FUN34 of C. graminicola and $C$. higginsianum (O'Connell et al. 2012). Three $C$. gloeosporiodes genes of the $M E P$ family-MEPA, $M E P B$, and $M E P C$-also shared 55 to $60 \%$ homology with published sequences of methyl ammonium transporters (Miyara et al. 2012). Protein analysis predicted the presence of 11 TMD in $M E P A$ and $M E P C$, similar to the predictions in Saccharomyces cerevisiae (Lengeler et al. 2000; Rohde and Cardenas 2004), whereas only nine TMD were predicted for $M E P B$.

$M E P$ genes are strictly regulated by the nitrogen regulator AREA (Teichert et al. 2008). Similarly, the four AMT/MEP genes of Aspergillus nidulans are differentially regulated in response to nitrogen status of the cell but their full expression requires the function of the GATA transcription factor $A R E A$

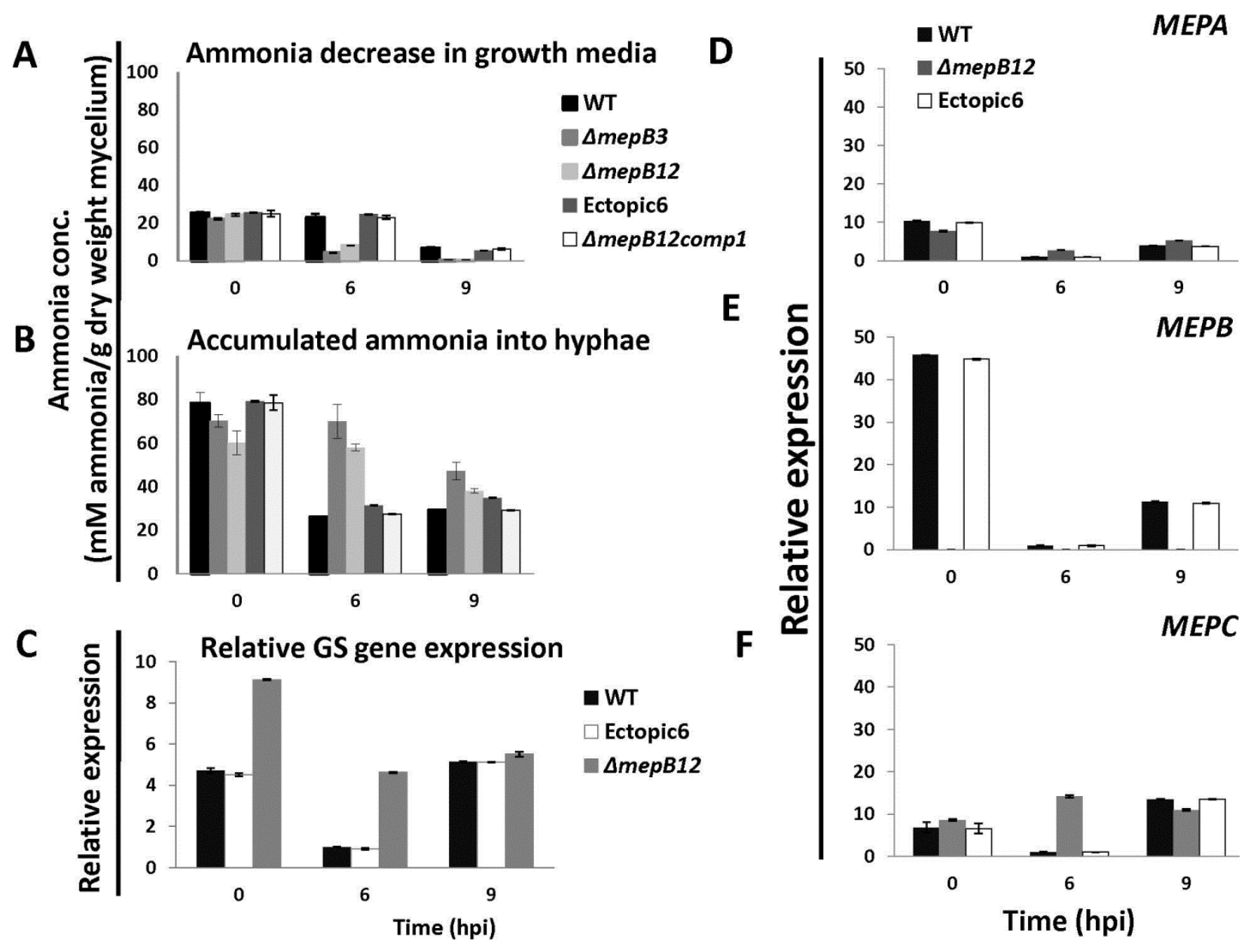

Fig. 5. Ammonia uptake and secretion and $M E P A, M E P B$, and $M E P C$ expression analysis for mycelia of Colletotrichum gloeosporioides wild-type (WT), ectopic, complemented, and $\triangle m e p B$ strains. A, Ammonia concentration in the growth medium (mM ammonia per gram dry weight of mycelium). B, Ammonia concentration inside the fungal mycelium (mM ammonia per gram dry weight of mycelium). C, Relative expression of glutamine synthetase (GS). D, E, and $\mathbf{F}$, Relative expressions of $M E P A, M E P B$, and $M E P C$, respectively. Relative expressions for the different treatments were compared with the lowest expression in the different treatments, which was given a value of 1 . Spores of $C$. gloeosporioides were inoculated into primary medium and, 3 days later, mycelium was transferred to secondary medium amended with $10 \mathrm{mM} \mathrm{NH}_{4} \mathrm{Cl}$ and analyzed at various intervals postinoculation. Average \pm standard deviation of three technical replications of one single biological experiment out of three repeated experiments is presented. 
(Monahan et al. 2006). Promoter analysis of AMET and MEPB in $C$. gloeosporioides indicated the presence of one and seven AREA-binding motifs, respectively, suggesting their possible regulation in $C$. gloeosporioides as well (Monahan et al. 2006). To further demonstrate the importance of AREA in ammonia export, Alkan and associates (2009) developed Colletotrichum $\Delta$ areA mutant strains that were impaired in ammonia secretion and attenuated in decay development. This suggested that modulation of ammonia accumulation by either $A M E T$ and $M E P B$ or the transcription factor $A R E A$ is a critical factor contributing to Colletotrichum pathogenicity on fruit. However, $M E P B$ is also regulated by $P A C C$ during the alkalinization process induced by ammonia and is downregulated in $\triangle p a c C$ mutants, indicating the presence of more than one mechanism of nitrogen-metabolism regulation during the colonization process of Colletotrichum spp. (Miyara et al. 2010).

Functional analysis of C. gloeosporioides AMET and MEPB genes encoding for ammonium transporters by gene knockout showed mutant strains with reduced pathogenicity on avocado fruit and confirmed early results suggesting that attenuation of ammonia secretion reduces pathogenicity (Alkan et al. 2008; Miyara et al. 2010). Comparison of the attenuation of pathogenicity by the $A M E T$ and $M E P B$ knockout strains indicated that, whereas the differences in colonization between the WT and $\triangle m e p B$ strains were observed within 5 to 7 days postinoculation with up to $80 \%$ inhibition of pathogenicity, differences between the WT and $\Delta$ amet strains were observed
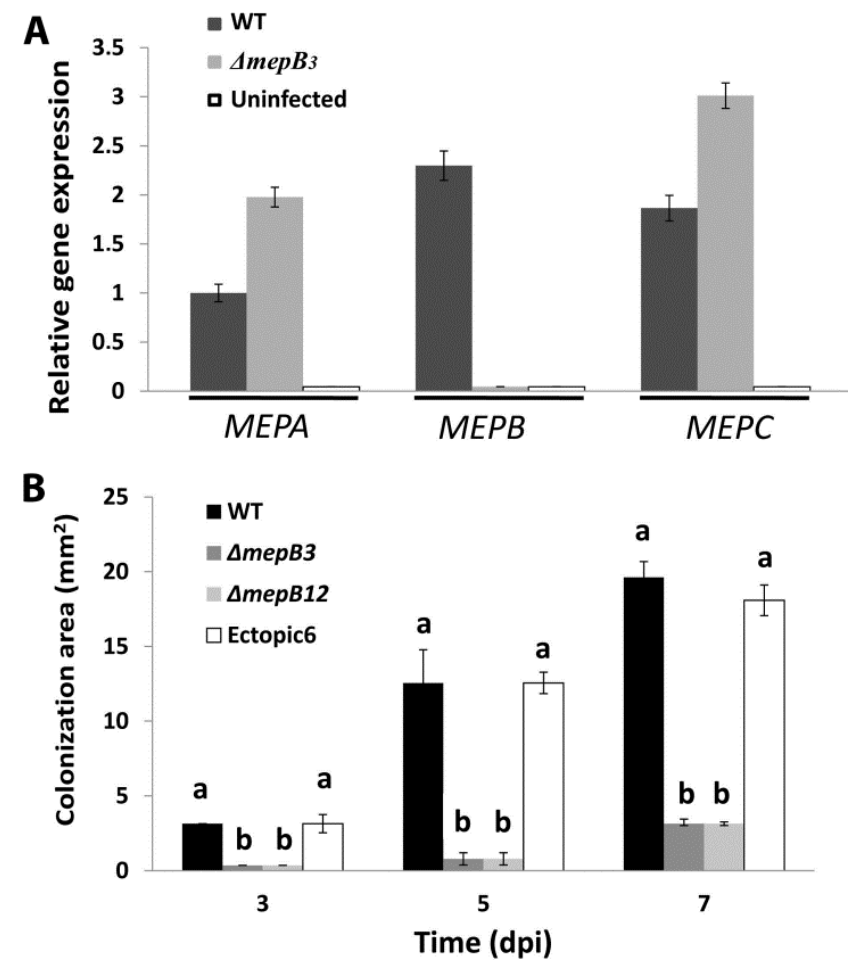

Fig. 6. Expression analysis of $M E P A, M E P B$, and $M E P C$ in the wild-type (WT) and $\triangle m e p B_{3}$ strains on inoculated pericarp of 'Fuerte' avocado fruit. A, Six days after inoculation of the WT, ectopic, and $\triangle m e p B$ strains on avocado pericarp, samples for relative expression determination by quantitative reverse-transcriptase polymerase chain reaction (qRT-PCR) were taken from inoculated fruit and $\mathbf{B}$, the colonized area was evaluated. Values of RT-PCR were normalized against $18 S$ rRNA. Relative expressions in the different treatments were compared with that of MEPA in the WT strain, which was given a value of 1 . Average \pm standard deviation of relative expression from three replications of one treatment is presented. The figure presents decay development of WT, mutant $\Delta m e p B_{3}$ and $\Delta m e p B_{12}$, and Ectopic $_{6}$ strains after inoculation (on the pericarp) of unpeeled freshly harvested avocado fruit. Average \pm standard deviation of colonized areas on 10 infected fruit after inoculation is presented.
13 to 15 dpi with only $50 \%$ inhibition of pathogenicity, suggesting a stronger contribution of ammonia accumulation by the $M E P B$ versus $A M E T$ genes.

In $C$. gloeosporioides, the relative expression of $M E P$ genes during growth in vitro under conditions of pathogenicity clearly showed overexpression of $M E P B$ in all cases; the highest tran-

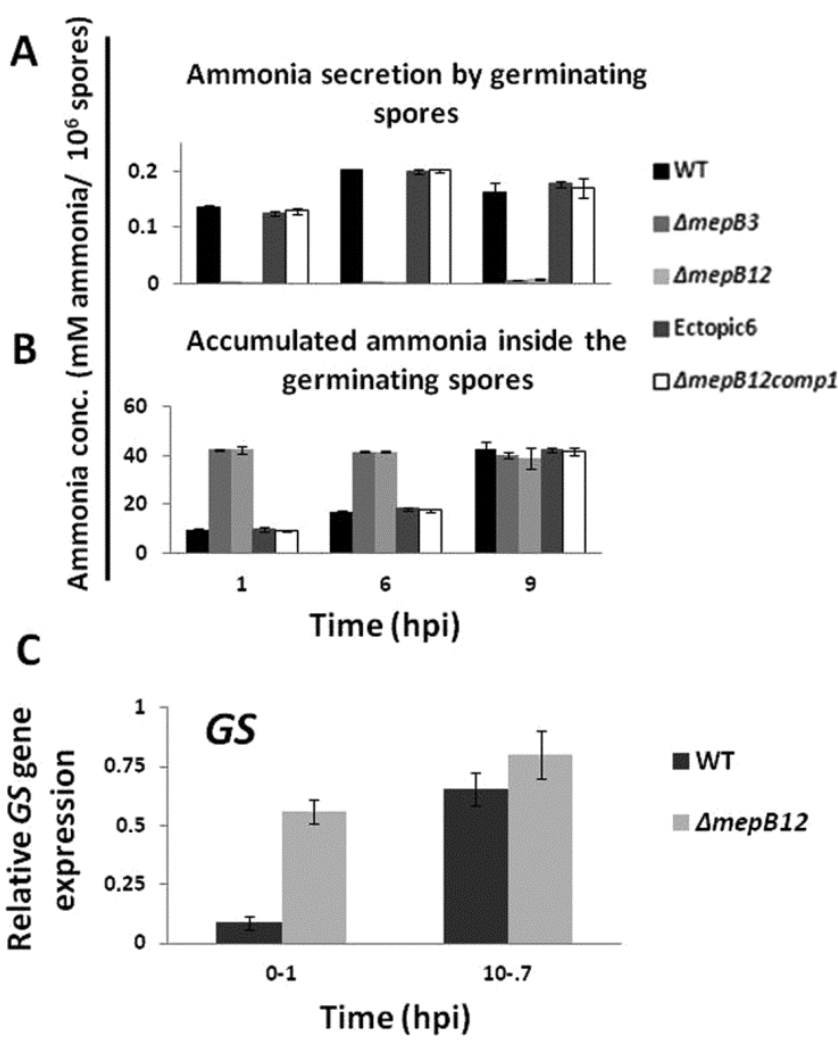

Fig. 7. Ammonia accumulation by spores of Colletotrichum gloeosporioides wild-type (WT), ectopic, complemented, and $\triangle m e p B$ strains. A, Outside the germinating spores. B, Inside the germinating spores. C, Glutamate synthetase $(G S)$ transcript expression. Spores were subjected to germination for 1 to $9 \mathrm{~h}$ in water on a stable hard surface and the amounts of ammonia secreted and accumulated in the spores were analyzed after various intervals postgermination. Average \pm standard deviation of three technical replications of one single biological experiment out of three repeated experiments is presented.

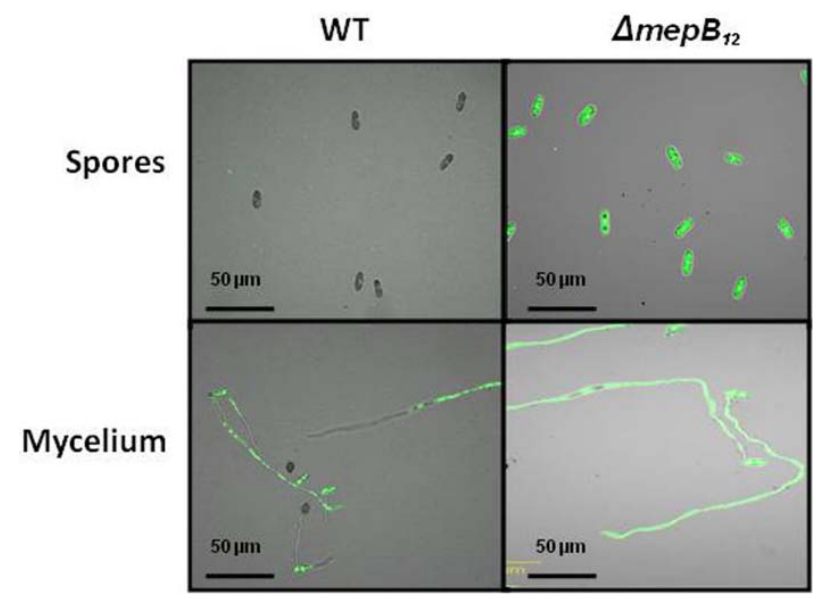

Fig. 8. Alkalinization determined by fluorescence of wild-type (WT) and $\triangle$ mep $B_{12}$ Colletotrichum gloeosporioides spores containing 2',7'-bis(carboxyethyl)-5(6)-carboxyfluorescein dye $5 \mathrm{~h}$ after germination induction on a hard surface. Spores and germinated $\Delta m e p B_{12}$ spores showed enhanced alkalinization as determined by the strong fluorescence compared with the WT strain. 
script expression was found under starvation, as well as during fungal colonization. However, $M E P B$-deleted strains revealed fourfold enhanced ammonia uptake into the fungal hyphae and reduced accumulation of ammonia in the medium. This might result from either inactivation of the $M E P B$ transporter protein or upregulation of $M E P A$ and $M E P C$ transcripts. Upregulation of $M E P A$ and, especially, $M E P C$ was observed when the $\triangle m e p B$ strains were inoculated in cultures (Fig. $5 \mathrm{D}$ to F) and on avocado fruit (Fig. 6), suggesting that they contribute to the internal accumulation of ammonia by the $\triangle m e p B$ strain but they slightly differ, probably because of the wide number of nitrogen sources

Table 1. Percentage germination and appressorium formation by wild-type (WT) and $\triangle m e p B$ strains in the presence of water and volatile ammonia ${ }^{\mathrm{a}}$

\begin{tabular}{|c|c|c|c|c|}
\hline \multirow[b]{2}{*}{ Strains } & \multicolumn{2}{|c|}{ Germination $(\% \pm \mathrm{SD})$} & \multicolumn{2}{|c|}{ Appressoria $(\% \pm$ SD) } \\
\hline & $\mathrm{H}_{2} \mathrm{O}$ & $\mathrm{NH}_{4} \mathrm{Cl}$ & $\mathrm{H}_{2} \mathrm{O}$ & $\mathrm{NH}_{4} \mathrm{Cl}$ \\
\hline WT & $93 \pm 2$ & $97 \pm 1.2$ & $89 \pm 3.5$ & $96 \pm 1.5$ \\
\hline$\Delta m e p B_{3}$ & $90 \pm 1$ & $88 \pm 5.1$ & $20 \pm 1.5$ & $44 \pm 0.5$ \\
\hline$\Delta m е р B_{12}$ & $90 \pm 2$ & $83 \pm 5.5$ & $24 \pm 1.5$ & $48 \pm 1$ \\
\hline Ectopic $_{6}$ & $92 \pm 3$ & $95 \pm 5.0$ & $90 \pm 3.5$ & $95 \pm 1.5$ \\
\hline
\end{tabular}

${ }^{\text {a }}$ Spores were subjected to germination in a $10-\mu \mathrm{l}$ water drop containing $10^{6}$ spores $\mathrm{ml}^{-1}$ on a glass slide. In the ammonia treatment $\left(\mathrm{NH}_{4} \mathrm{Cl}\right), 5$ $\mathrm{mM}$ exogenous volatile ammonia at $\mathrm{pH} 8.5$ was supplied and effects were compared with water control. At $14 \mathrm{~h}$ postinduction, the spores were stained with bromophenol blue and the percentages of germination and appressorium formation were determined. Average data \pm standard deviation (SD) are presented.

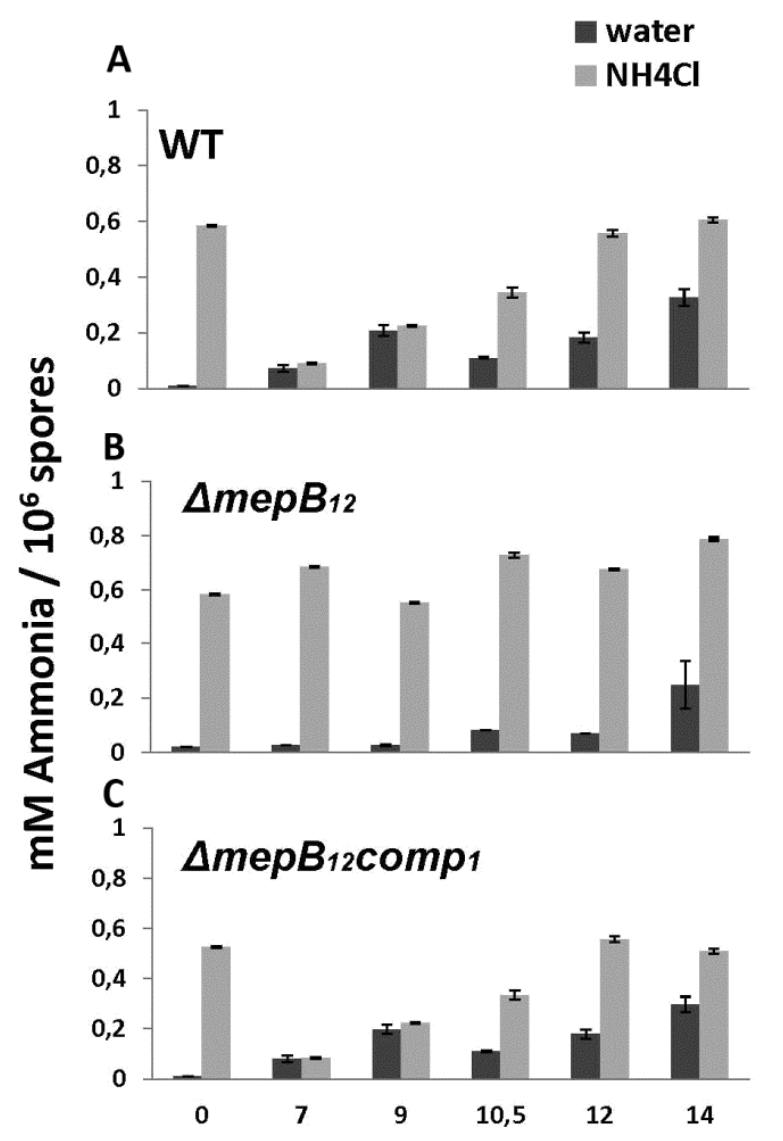

present in the fruit. However, the $80 \%$ reduction in avocado pericarp colonization by the $\triangle m e p B$ strains indicated that the pathogenicity of $C$. gloeosporioides is mainly affected by downregulation of $M E P B$ and not by upregulation of $M E P A$ and $M E P C$. These results contrast with the effects of a single deletion of three $M E P$ genes in Saccharomyces spp. or two MEP
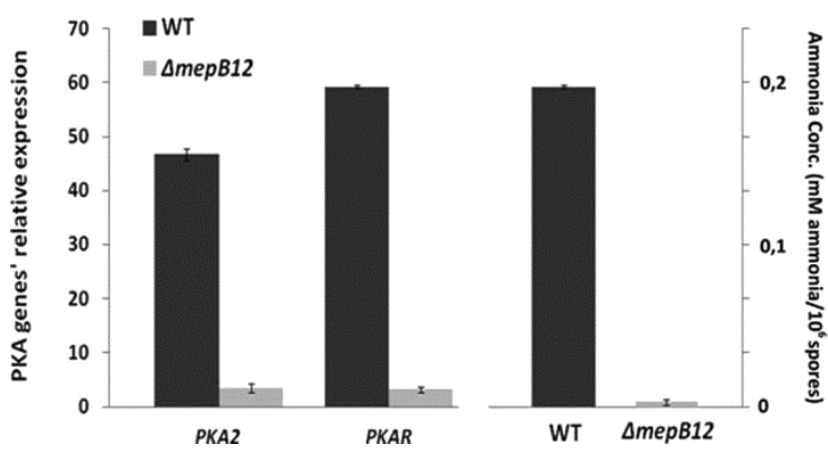

Fig. 10. Relative expressions of $P K A 2$ and $P K A R$ and ammonia accumulation by germinating Colletotrichum gloeosporioides spores. Quantitative relative expression of $P K A 2$ and $P K A R 8 \mathrm{~h}$ after initiation of germination (i.e., at full germination). Values of reverse-transcriptase polymerase chain reaction were normalized against $18 S$ rRNA. Relative expression in the different treatments was compared with the lowest value of expression in the respective treatments, which was given a value of 1 . Average \pm standard deviation of three technical replications of one single biological experiment out of three repeated experiments is presented.

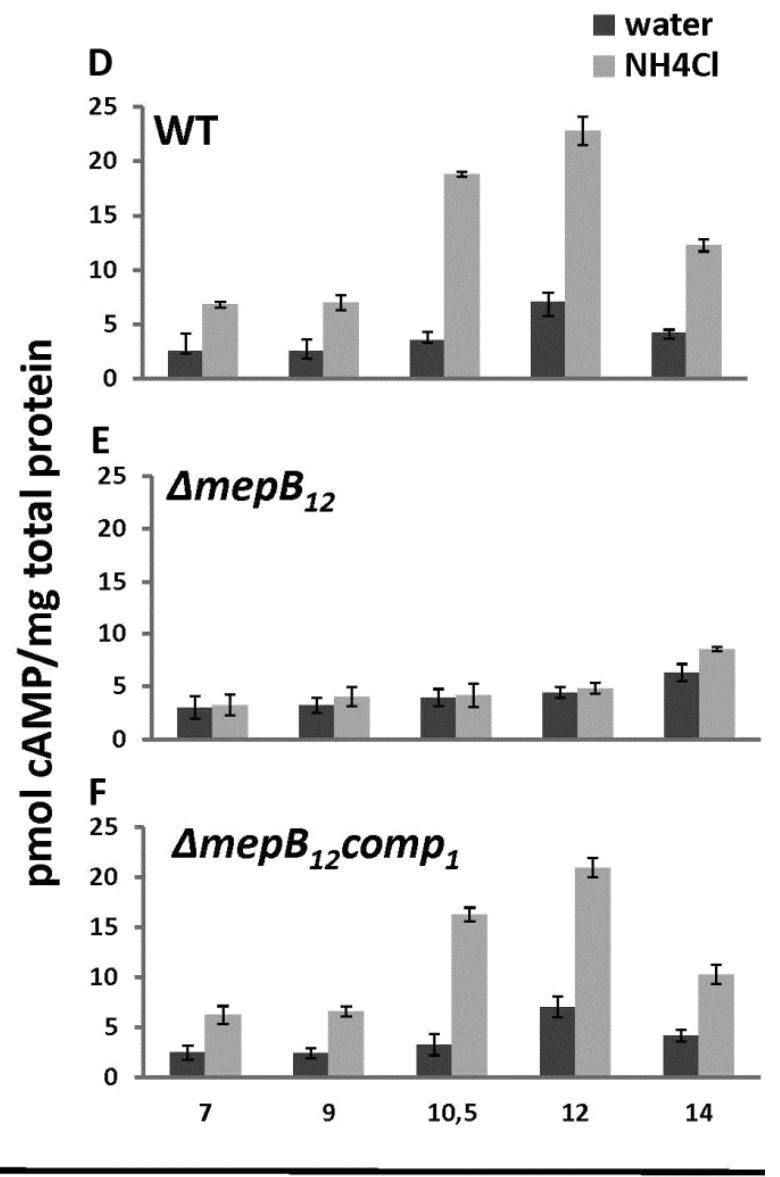

\section{Time (hpi)}

Fig. 9. A to C, Ammonia uptake and efflux and D to F, cAMP activity by germinating Colletotrichum gloeosporioides spores of the wild-type (WT), $\triangle m e p B_{12}$, and complemented strains. Spores of WT, $\triangle m e p B_{12}$, and complemented strains were subjected to germination for 1 to $14 \mathrm{~h}$ in water with added $\mathrm{NH}_{4} \mathrm{Cl}(5 \mathrm{mM})$ on a stable hard (glass) surface and, after various intervals, the concentration (pmol) of accumulated cAMP in the spores was determined. Values were normalized against weight (milligrams) of total cell protein. Average \pm standard deviation of three technical replications of one single biological experiment out of three repeated experiments is presented. 
genes in Aspergillus spp., which did not elicit any effect or rendered the strains unable to grow under ammonium concentrations of less than $10 \mathrm{mM}$ (Brendon et al. 2002; Magasanik 2005; Marini et al. 1997).

\section{Do $A M E T$ and $M E P B$ participate in nitrogen import and export?}

The molecular mechanisms activating transporter-mediated ammonium regulation are not fully known. The fungal ammonium permeases have evolved regulatory functions of activation under starvation conditions, resulting in physiological and morphogenetic processes that affect fungal development. In $S$. cerevisiae, the plasma-membrane-localized permease MEP2 is able to sense environmental nutritional limitations that might modulate pathogenicity (Forsberg and Ljungdahl 2001; van Nuland et al. 2006) or pseudohyphal growth (Lorenz and Heitman 1998). CaMEP2 in Candida albicans induces filamentous growth under nitrogen-limited conditions, via activation of both mitogen-activated protein kinase and the Ras1cAMP-dependent pathways (Biswas and Morschhäuser 2005). Similarly, in Ustilago maydis, the expression of two ammonium permease-encoding genes is required for the induction of filamentous growth (Smith et al. 2003).

In most cases, $M E P$ transporters have been assayed by direct ammonia uptake (Javelle et al. 2003; Teichert et al. 2008). This is a simple and efficient assay but is not always representative of the complex processes occurring during uptake and secretion of ammonia (Miyara et al. 2010, 2012) in developing fungal cells. To investigate possible ammonia transport in C. gloeosporioides, a real-time assessment of uptake and secretion of ammonia was carried out on developing hyphae and the germinated spores. Functional analysis of $\Delta a m e t$ and $\triangle m e p B$ strains showed no effect on fungal growth but $50 \%$ inhibition of ammonia accumulation in the culture media (Table 2). Knockout of $M E P B$ showed immediate, 2.7-fold enhanced ammonia accumulation in the hyphae compared with the WT strains whereas no differential accumulation was observed between the $\Delta a m e t$ and control strains. This might indicate that, in colonizing mycelia of $C$. gloeosporioides, $M E P B$ is an important regulator of efflux or uptake of ammonium and that, in the $\triangle m e p B$ strains, $M E P A$ and $M E P C$ can contribute to the uptake but not the efflux. The functional reduction of ammonia secretion by $\triangle a m e t$ and $\triangle m e p B$ strains affects fungal pathogenicity via modulation of ammonia secretion to the colonized tissue, reduction of the alkalinization process, and a reduction in fungal gene expression of Colletotrichum pathogenicity factors (Table 2) (Alkan et al. 2009, 2012; Miyara et al. 2010).

The balance of ammonia influx and efflux in germinating spores was different from that in the mycelium. Whereas the WT spores exhibited a basic level of ammonia secretion $(0.1$ $\mathrm{mM} 10^{6}$ spores $^{-1}$ ) during the $9 \mathrm{~h}$ of germination, significant uptake-from 8 to $45 \mathrm{mM} 10^{6}$ spores $^{-1}$ —was observed during the same period. $\triangle m e p B$ mutants did not secrete ammonia; on the contrary, they showed an immediate accumulation of ammonia inside the spore, as confirmed by fluorescence microscopy, to the levels found in the WT $9 \mathrm{~h}$ postinitiation of spore germination. This bidirectional activity of ammonia transporters has been reported in Salmonella typhimurium (AmtB), where the capability to take up and release ammonium into the medium by outward diffusion is dependent on growth on an alternative nitrogen source, such as arginine (Javelle et al. 2005; Soupene et al. 1998, 2002). Soupene and associates (2002) claimed that this type of outward diffusion requires a $\mathrm{pH}$ of 7.0 and a low concentration of ammonia $(\leq 50 \mathrm{nM})$ in the culture media. However, the high level of ammonia inside the germinating spores of the $\triangle m e p B$ strain and the lack of ammonia secretion suggest deregulation of ammonia transport. Interestingly, the fungus developed a simple mechanism for ammonia detoxification in both the hyphae and germinating spores, via increased relative expression of $G S$, which also probably contributed to the reduction in outward diffusion of the fungal-produced ammonia by the $\Delta m e p B$ strain.

All of these findings are consistent with the view that ammonium permease proteins increase the rate of ammonium uptake across the cytoplasmic membrane (von Wiren and Merrick 2004) during spore germination, as a mechanism for the induction of appressorium formation (Miyara et al. 2010, 2012). Only those permeases that modulate uptake of ammonia modulate that mechanism of appressoria formation (Table 2). However, the critical role of the cAMP and PKA signaling pathway in appressorium formation and pathogenesis of several fungal pathogens (Adachi and Hamer 1998; Choi and Dean 1997; Gold et al. 1997; Kronstad 1997; Lee et al. 2003; Lee and Dean 1994; Mitchell and Dean 1995; Taylor et al. 1990; Xu 2000) led us to check whether the inhibition of appressorium formation in the mutants with compromised ammonium transport capacity is dependent on lack of activation of the cAMP and PKA signaling process. Our results indicated that the strain with compromised ammonium transport is not able to import ammonia to enhance cAMP activity, exhibits reduced expression of $P K A 2$ and $P K A R$, and shows reduced appressorium formation compared with the WT strain that exhibited rapid ammonia uptake, increased cAMP activity, enhanced expression of $P K A 2$ and $P K A R$, and exhibited a high percentage of appressorium formation. These results suggest that ammonia secretion by developing hyphae contributes to necrotrophic colonization by Colletotrichum spp. (Miyara et al. 2012; O'Connell et al. 2012) but, at early stages of spore germination, ammonia modulates the induction of appressorium formation as a signal for appressorium formation and pathogenicity (Miyara et al. 2010).

\section{MATERIALS AND METHODS}

Fungal isolates, media, and growth conditions.

Single-spore cultures of the WT Cg-14 isolate of $C$. gloeosporioides, obtained from a decayed avocado (Persea ameri-

Table 2. Comparison of the functional activity of MEPB and AMET1

\begin{tabular}{|c|c|c|}
\hline \multirow[b]{2}{*}{ Phenotypic response } & \multicolumn{2}{|c|}{ Strains } \\
\hline & АmepB & Damet1 \\
\hline Spore germination & No effect & No effect \\
\hline Appressoria formation & Inhibited & No effect \\
\hline Fungal growth & No effect & No effect \\
\hline Export of ammonia & Inhibited & Inhibited \\
\hline Import of ammonia & Inhibited & Minor effect \\
\hline Accumulation and $\mathrm{pH}$ increase out of the fungus in the inducing media & Inhibited & Inhibition \\
\hline Pathogenicity on avocado fruit & Inhibition & Inhibition \\
\hline Mode of action & $\begin{array}{l}\text { Inhibition of appressoria formation } \\
\text { and inhibition of alkalinization that } \\
\text { leads to reduced colonization }\end{array}$ & $\begin{array}{l}\text { Inhibition of alkalinization that leads } \\
\text { to reduced colonization }\end{array}$ \\
\hline
\end{tabular}


cana 'Fuerte') fruit in Israel, and all strains used in the present study (Table 1) were routinely cultured on $\mathrm{M}_{3} \mathrm{~S}$ agar ( $\mathrm{Tu}$ 1985). $\mathrm{M}_{3} \mathrm{~S}$ medium without agar (primary medium) was also used for initial growth of the fungus, prior to its exposure to various nutritional induction factors. The medium contained $2.5 \mathrm{~g}$ of $\mathrm{MgSO}_{4} \cdot 7 \mathrm{H}_{2} \mathrm{O}$ (Merck, Darmstadt, Germany), $2.7 \mathrm{~g}$ of $\mathrm{KH}_{2} \mathrm{PO}_{4}$ (Merck), $1 \mathrm{~g}$ of Bacto peptone (Becton, Dickinson, Sparks, MD, U.S.A.), $1 \mathrm{~g}$ of Bacto yeast extract (Becton, Dickinson), $10 \mathrm{~g}$ of sucrose (Duchefa Biochemie, Haarlem, the Netherlands), and $25 \mathrm{mg}$ of chloramphenicol (Sigma-Aldrich, St. Louis) per liter. The cultures were incubated for 3 days at 22 to $24^{\circ} \mathrm{C}$ in a shaking incubator at $150 \mathrm{rpm}$ and were harvested by filtration through a sterile Büchner funnel fitted with filter paper. The hyphal mat was washed twice with $40 \mathrm{ml}$ of sterile distilled water. The washed mycelia were resuspended in $40 \mathrm{ml}$ of fresh SM containing $4 \mathrm{~g}$ of $\mathrm{KH}_{2} \mathrm{PO}_{4}, 2 \mathrm{~g}$ of $\mathrm{MgSO}_{4}$. $7 \mathrm{H}_{2} \mathrm{O}, 0.3 \mathrm{~g}$ of $\mathrm{CaCl}_{2} \cdot 2 \mathrm{H}_{2} \mathrm{O}$ (Sigma-Aldrich), $10 \mathrm{mg}$ of $\mathrm{FeCl}_{3}$ (Sigma-Aldrich), and $50 \mathrm{mM}$ glucose (Duchefa Biochemie) per liter. To monitor ammonia consumption, SM was amended with 5 to $10 \mathrm{mM} \mathrm{NH}_{4} \mathrm{Cl}$ (Sigma-Aldrich) as a nitrogen source (ammonia-consuming medium). The medium was buffered with $50 \mathrm{mM}$ phthalate-hydroxide buffer (Sigma-Aldrich) to obtain an initial $\mathrm{pH}$ between 4.0 and 7.0. The initial $\mathrm{pH}$ for each flask was determined after the medium had been autoclaved but prior to inoculation. At least three biological repetitions for each experiment with three technical replicates were carried out. Low differences between the biological repetitions (with 2 to $3 \%$ between them) were usually found. A single biological experiment with three technical repetitions showing the differences between treatments are presented for all the experiments.

\section{Analysis of $C$. gloeosporioides $M E P B$ mutants.}

Generation of $M E P B$ knockout strains is described in detail elsewhere (Miyara et al. 2012). The transformants were regrown as single colonies on $\mathrm{M}_{3} \mathrm{~S}$ agar. For genomic DNA extraction, a plug of grown mycelium was taken for extraction with Pure Yeast DNA Purification Kit Master (Epicenter, New London, CT, U.S.A.).

\section{Fruit inoculation.}

Freshly harvested Fuerte avocado fruit from an orchard in Kibbutz Givat Brenner, Israel, were used for inoculation. Spores of the various $C$. gloeosporioides strains were inoculated onto the avocado fruit peel by placing $7 \mu \mathrm{l}$ of a conidial suspension containing $10^{6}$ conidia $\mathrm{ml}^{-1}$ on each of three longi- tudinally spaced inoculation spots on each side of 10 different fruit per treatment (i.e., 60 inoculation replicates per treatment). To inoculate fruit on the mesocarp, a 1- to 2-mm strip of peel tissue was removed and $7-\mu l$ aliquots of a conidial suspension containing $10^{6}$ conidia $\mathrm{ml}^{-1}$ were placed into 1 -mm-deep, 1mm-diameter inoculation spots in the fruit mesocarp. In each treatment, five inoculation spots, longitudinally spaced on each side of 10 different fruit, were inoculated. For detection of gene expression during assessment of avocado decay development, a bulk-inoculation method similar to that described by Alkan and associates (2008) was used. Briefly, 5-day-old mycelium of $C$. gloeosporioides strains was cultured for 3 days in $\mathrm{M}_{3} \mathrm{~S}$ medium and was then washed twice with sterile water. The washed mycelium was inoculated into holes, $2 \mathrm{~mm}$ deep and $5 \mathrm{~mm}$ in diameter, pierced into the mesocarp. After inoculation, the fruit were incubated for $24 \mathrm{~h}$ at $22^{\circ} \mathrm{C}$ and $95 \%$ relative humidity in covered plastic containers containing wet paper towels, then were further incubated until symptoms were observed. For all experiments, the average decay diameters \pm standard deviation are reported. The inoculation experiments were repeated three times, and one representative experiment is presented. The decayed tissue was sliced from the fruit, frozen in liquid nitrogen, and saved at $-80^{\circ} \mathrm{C}$ pending RNA extraction.

\section{Spore-germination and appressorium-induction assay.}

For RNA extraction and ammonia detection in germinating spores producing or not producing appressoria (i.e., undergoing "pathogenic" or "saprophytic" germination, respectively, according to Barhoom and Sharon [2004]), 10-ml samples of suspensions of $C$. gloeosporioides conidia containing $10^{6}$ conidia $\mathrm{ml}^{-1}$ of double-distilled water (DDW) were spread onto 20 -cm-diameter petri dishes and were incubated for 12 to $14 \mathrm{~h}$. The germinated conidia were then harvested by scraping them off the petri dishes and centrifuging at 3,200 $\times g$ for $20 \mathrm{~min}$. The pellet containing conidia and appressoria was lyophilized and subjected to RNA extraction. The supernatant was used for ammonia detection. For appressorium-formation and maturation-detection experiments, $C$. gloeosporioides WT and $M E P B$-disruption isolates were observed on glass slides. Briefly, 5 to $25 \mu \mathrm{l}$ of a conidial suspension of each isolate in DDW, containing $10^{6}$ conidia $\mathrm{ml}^{-1}$, was placed on each of five glass slides that were kept on filter paper moistened with DDW or volatile ammonia in a humid chamber. After 12 to $16 \mathrm{~h}$ of incubation, conidial germination and appressorium development were observed in three microscope fields in each of five cells per slide. The spores were stained with bromophenol blue

Table 3. Primers used in this study

\begin{tabular}{lll}
\hline Number & Primer name $^{\mathbf{a}}$ & Sequence $^{\prime} \mathbf{- 3}^{\prime}$ \\
\hline 1 & Cg 18S F & GTG AGG CCC TCA AAG GTA GTG G \\
2 & Cg 18S R & GGA TCC CAG TGC GAG ACG T \\
3 & Cg qRT-PCR MEPA F & AGC CTC GTT GTC CAT GTC ATT C \\
4 & Cg qRT-PCR MEPA R & AGG CCG AGA TTC TAG GTA TCG AC \\
5 & Cg qRT-PCR MEPB F & ATG GTC TTC GCC TTC ATC TGG \\
6 & Cg qRT-PCR MEPB R & AGG AAA TGT GGA CGG GAG TA \\
7 & Cg qRT-PCR MEPC F & ACA CCG TCG AGA CCG ATA AT \\
8 & Cg qRT-PCR MEPC R & CGA TGA CTC CCT CGA TGT CT \\
9 & Cg qRT-PCR MAPCK1 F & GTT GCA TGT GCG CCT GG \\
10 & Cg qRT-PCR MAPCK1 R & TGG TAC CGT GCT CCC GAG \\
11 & HYG 5'R ctrl & GCC TGG ACG ACT AAA CCA AA \\
12 & HYG 3'F ctrl & CTG GAT CCA TCT CCT TGC AT \\
13 & AMET 5'F & GGG GAC AAC TTT GTA TAG AAA AGT TGG CGG CCG CGG ACG TGC ATA CAT CTG GTG \\
14 & AMET 5'R & GGG GACTGC TTT TTT GTA CAA ACT TGC GGT TCG TAT TGC GTT TCT T \\
15 & AMET 3'F & GGG GAC AGC TTT CTT GTA CAA AGT GGA CCA TTG GAT TAC AGG GAG AT \\
16 & AMET 3'R & GGG GAC AAC TTT GTA TAA TAA AGT TGG CGG CCG CAG GAT GAT TAG CAA ATG GAA TC \\
17 & AMET 5'F ctrl & AAT GGC CAC GCA CGA G \\
18 & AMET 3 $^{\prime} \mathrm{F}$ ctrl & CCC TAT TGC CAA AGC ACA TT \\
\hline
\end{tabular}

${ }^{a}$ qRT-PCR, primer used in real-time quantitative reverse-transcriptase polymerase chain reaction experiments. 
and the percentages of germination and appressorium formation of 300 spores in 10 repeats were determined. Maturation of appressoria was defined according to melanization level; only fully melanized appressoria were considered mature, hyalineless pigmented appressoria were considered immature. External ammonia was supplied to the humid chamber as $5 \mathrm{mM} \mathrm{NH}_{4} \mathrm{Cl}$ at $\mathrm{pH} 8.5$ without contacting the spore suspension.

\section{Analysis of $C$. gloeosporioides MEPA, MEPB, MEPC, PKA2, and $P K A R$.}

The genes encoding $C$. gloeosporioides MEPA, MEPB, $M E P C, P K A 2$, and $P K A R$ were analyzed by D. Prusky from $C$. gloeosporioides genome sequences (unpublished) and were deposited in GenBank under the following accession numbers: $M E P A$, JN660155; MEPB, JN660156; MEPC, JN660157; CPK2, JQ345691; and PKAR, JQ345692.

\section{Quantitative PCR analysis.}

The reverse-transcription reaction was performed on $1 \mu \mathrm{g}$ of total RNA with the Reverse-It first-strand synthesis kit (ABgene, Surrey, U.K.). Samples of cDNA were diluted 1:10 ( $\mathrm{vol} / \mathrm{vol}$ ) to the final template concentration for quantitative (q)PCR. Real-time qPCR was performed with the RotorGene 3000 system (Corbett Research, Sydney, Australia). PCR amplification was applied to $3.4 \mu \mathrm{l}$ of cDNA template in $10 \mu \mathrm{l}$ of a reaction mixture containing $5 \mu \mathrm{l}$ of Syber-Green amplification kit (ABgene) and $300 \mathrm{nM}$ primers. PCR conditions were initial denaturation for $15 \mathrm{~min}$ at $94^{\circ} \mathrm{C}, 40$ denaturation cycles of $10 \mathrm{~s}$ at $99^{\circ} \mathrm{C}$ and annealing for $15 \mathrm{~s}$ at $60^{\circ} \mathrm{C}$ and for $6 \mathrm{~s}$ at $80^{\circ} \mathrm{C}$, extension at for $20 \mathrm{~s} 72^{\circ} \mathrm{C}$, and melting at 72 to $99^{\circ} \mathrm{C}$. The samples were subjected to melting curve analysis with the RotorGene program. All samples were normalized to $18 \mathrm{~S}$ rRNA gene levels in the same qPCR, and the values were expressed relative to a calibration sample. The forward and reverse primers for all of the genes are provided in Table 3. The experiment was repeated at least three times with similar results; the results of one biological experiment with three technical repetitions are presented.

\section{pH measurement and ammonia detection.}

The $\mathrm{pH}$ in $0.5-\mathrm{ml}$ aliquots taken at various times after fungal inoculation was measured with a Thermo-Orion Model 9810BN microcombination $\mathrm{pH}$ electrode (Thermo Fisher Scientific, Waltham, MA, U.S.A.). Ammonia was detected colorimetrically with an ammonium test kit (Merck). Samples $(0.1 \mathrm{ml})$ of the culture media were diluted with $4.9 \mathrm{ml}$ of DDW, and the concentration of ammonia was determined according to the manufacturer's instructions. Briefly, the sample containing ammonium was adjusted to $\mathrm{pH} 13$ so that the ammonium was transformed to ammonia, which could then be detected colorimetrically at $690 \mathrm{~nm}$. Concentrations were reported as millimoles of ammonia per gram (dry weight) of mycelium. For determination of ammonia accumulation and alkalinization inside the germinated spores, spores were stained with the fluorescent dye BCECF (Molecular Probes, Invitrogen, Leiden, The Netherlands), according to Alkan and associates (2008).

\section{Assay for spore cAMP activity.}

To measure cAMP activity in the spores, the WT strain was grown on $20-\mathrm{cm}$ petri dishes as described above. Germinating spores were harvested, frozen in liquid nitrogen, ground, homogenized in 10 volumes of $0.1 \mathrm{M} \mathrm{HCl}$, and centrifuged at $600 \times g$. cAMP level was measured with the Direct cAMP enzyme immunoassay kit (Sigma-Aldrich) according to the manufacturer's instructions. Protein concentration was determined with the Bio-Edit protein assay kit (Bio-Rad, Foster
City, CA, U.S.A.). The intraspore cAMP concentration in total protein was expressed as picomoles per milligram.

\section{LITERATURE CITED}

Adachi, K., and Hamer, J. E. 1998. Divergent cAMP signaling pathways regulate growth and pathogenesis in the rice blast fungus Magnaporthe grisea. Plant Cell 10:1361-1373.

Alkan, N., Fluhr, R., Sherman, A., and Prusky, D. 2008. Role of ammonia secretion and $\mathrm{pH}$ modulation on pathogenicity of Colletotrichum coccodes on tomato fruit. Mol. Plant-Microbe Interact. 21:1058-1066.

Alkan, N., Fluhr, R., Sagi, M., Davydov, O., and Prusky, D. 2009. Ammonia secreted by Colletotrichum coccodes affects host NADPH oxidase activity enhancing cell death and pathogenicity in tomato fruits. Mol. Plant-Microbe Interact. 22:1484-1491.

Alkan, N., Fluhr, R., and Prusky, D. 2012. Colletotrichum coccodes infection of ripe and unripe tomato fruit is modulated by ammonium secretion through salicylic and jasmonic acid pathways leading to PCD and differential colonization. Mol. Plant-Microbe Interact. 25:85-96.

Barad, S., Horowitz, S., Sherman, L., and Prusky, D. 2012. Penicillium expansum glucose oxidase-encoding gene, gox 2 , is essential for gluconic acid production and acidification during colonization of deciduous fruits. Mol. Plant-Microbe Interact. 25:779-788.

Barhoom, S., and Sharon, A. 2004. cAMP regulation of pathogenic and saprophytic fungal spore germination. Fungal Genet. Biol. 41:317-326.

Biswas, K., and Morschhäuser, J. 2005. The Mep2p ammonium permease controls nitrogen starvation-induced filamentous growth in Candida albicans. Mol. Microbiol. 56:649-669.

Brendon, J., Monahan, J., Fraser, J. A., Hynes, M. J., and Davis, M. A. 2002. Isolation and characterization of two ammonium permease genes, meaA and mepA, from Aspergillus nidulans. Eukaryot. Cell 1:85-94.

Choi, W. B., and Dean, R. A. 1997. The adenylate cyclase gene MAC1 of Magnaporthe grisea controls appressorium formation and other aspects of growth and development. Plant Cell 9:1973-1983.

Davidzon, M., Alkan, N., Kobiler, I., and Prusky, D. 2010. Acidification by gluconic acid of mango fruit tissue during colonization via stem end infection by Phomopsis mangiferae. Postharvest Biol. Technol. 55:71-77.

Diéguez-Uribeondo, J., Förster, H., and Adaskaveg, J. E. 2008. Visualization of localized pathogen-induced $\mathrm{pH}$ modulation in almond tissues infected by Colletotrichum acutatum using confocal scanning laser microscopy. Phytopathology 98:1171-1178.

Drori, N., Kramer-Haimovich, H., Rollins, J., Dinoor, A., Okon, Y., Pines, O., and Prusky, D. 2003. A combination of external pH and nitrogen assimilation affects secretion of the virulence factor pectate lyase by Colletotrichum gloeosporioides. Appl. Environ. Microbiol. 69:32583262.

Eshel, D., Miyara, I., Ailinng, T., Dinoor, A., and Prusky, D. 2002. pH regulates endoglucanase expression and virulence of Alternaria alternata in persimmon fruits. Mol. Plant-Microbe Interact. 15:774-779.

Forsberg, H., and Ljungdahl, P. O. 2001. Sensors of extracellular nutrients in Saccharomyces cerevisiae. Curr. Genet. 40:91-109.

Gold, S. E., Brogdon, S. M., Mayorga, M. E., and Kronstad, J. W. 1997. The Ustilago maydis regulatory subunit of a cAMP-dependent protein kinase is required for gall formation in maize. Plant Cell 9:1585-1594

Javelle, A., Morel, M., Rodriguez-Pastrana, B. R., Botton, B., Andre, B., Marini, A. M., Brun, A., and Chalot, M. 2003. Molecular characterization, function and regulation of ammonium transporters (Amt) and ammonium-metabolizing enzymes (GS, NADP-GDH) in the ectomycorrhizal fungus Hebeloma cylindrosporum. Mol. Microbiol. 47:411430 .

Javelle, A., Thomas, G., Marini, A. M., Krämer, R., and Merrick, M. 2005. In vivo functional characterization of the Escherichia coli ammonium channel AmtB: Evidence for metabolic coupling of AmtB to glutamine synthetase. Biochem. J. 390:215-222.

Kamaruddin, N., Bakar, F. A., Mahadi, N. M., and Murad, A. M. A. 2008. Isolation and characterization of a gene encoding the Colletotrichum gloeosporioides regulatory subunits for protein kinase A. J. Biol. Sci. 8:730-737.

Kojima, K., Kikuchi, T., Takano, Y., Oshiro, E., and Okuno, T. 2002. The mitogen-activated protein kinase gene MAF1 is essential for the early differentiation phase of appressorium formation in Colletotrichum lagenarium. Mol. Plant-Microbe Interact. 15:1268-1276.

Kramer-Haimovich, H., Servi, E., Katan, T., Rollins, J., Okon, Y., and Prusky, D. 2006. Effect of ammonia production by Colletotrichum gloeosporioides on pelB activation, pectate lyase secretion, and fruit pathogenicity. Appl. Environ. Microbiol. 72:1034-1039.

Kronstad, J. W. 1997. Virulence and cAMP in smuts, blasts and blights. Trends Plant Sci. 2:193-199.

Lee, N., D’Souza, C. A., and Kronstad, J. W. 2003. Of smuts, blasts, mil- 
dews, and blights: cAMP signaling in phytopathogenic fungi. Annu. Rev. Phytopathol. 41:399-427.

Lee, Y. H., and Dean, R. A. 1993. cAMP regulates infection structure formation in the plant pathogenic fungus Magnaporthe grisea. Plant Cell 5:693-700.

Lee, Y. H., and Dean, R. A. 1994. Hydrophobicity of contact surface induces appressorium formation in Magnaporthe grisea. FEMS (Fed. Eur. Microbiol. Soc.) Microbiol. Lett. 115:71-75.

Lengeler, K. B., Davidson, R. C., D'Souza, C., Harashima, T., Shen, W. C., Wang, P., Pan, X., Waugh, M., and Heitman, J. 2000. Signal transduction cascades regulating fungal development and virulence. Mol. Microbiol. Biol. Rev. 64:746-785.

Liebmann, B., Müller, M., Braun, A., and Brakhage, A. A. 2004. The cyclic AMP-dependent protein kinase A network regulates development and virulence in Aspergillus fumigatus. Infect. Immun. 72:5193-5203.

Lorenz, M. C., and Heitman, J. 1998. The MEP2 ammonium permease regulates pseudohyphal differentiation in Saccharomyces cerevisiae. EMBO (Eur. Mol. Biol. Organ.) J. 17:1236-1247.

Magasanik, B. 2005. The transduction of the nitrogen regulation signal in Saccharomyces cerevisiae. Proc. Natl. Acad. Sci. U.S.A. 102:1653716538.

Manteau, S., Abouna, S., Lambert, B., and Legendre, L. 2003. Differential regulation by ambient $\mathrm{pH}$ of putative virulence factors secretion by the phytopathogenic fungus Botrytis cinerea. FEMS (Fed. Eur. Microbiol. Soc.) Microbiol. Ecol. 43:359-366.

Marini, A. M., Soussi-Boudekou, S., Vissers, S., and Andre, B. 1997. A family of ammonium transporters in Saccharomyces cerevisiae. Mol. Cell Biol. 17:4282-4293.

Mitchell, T. K., and Dean, R. A. 1995. The cAMP-dependent proteinkinase catalytic subunit is required for appressorium formation and pathogenesis by the rice blast pathogen Magnaporthe grisea. Plant Cell 7:1869-1878.

Miyara, I., Shafran, H., Davidzon, M., Sherman, A., and Prusky, D. 2010. $\mathrm{pH}$ regulation of ammonia secretion by Colletotrichum gloeosporioides and its effect on appressorium formation and pathogenicity. Mol. PlantMicrobe Interact. 23:304-316.

Miyara, I., Shnaiderman, C., Meng, X., Vargas, W. A., Diaz-Minguez, J. M., Sherman, A., Thon, M., and Prusky, D. 2012. Role of nitrogenmetabolism genes expressed during pathogenicity of the alkalinizing Colletotrichum gloeosporioides and their differential expression in acidifying pathogens. Mol. Plant-Microbe Interact. 25:1251-1263.

Monahan, B. J., Askin, M. C., Hynes, M. J., and Davis, M. A. 2006. Differential expression of Aspergillus nidulans ammonium permease genes is regulated by GATA transcription factor AreA. Eukaryot. Cell 5:226237.

O'Connell, R., Thon, M. R., Hacquard, S., van Themaat, E. V. L., Amyotte, S. G., Kleemann, J., Torres, M. F., Damm, U., Buiate, E. A., Epstein, L., Alkan, N., Altmüller, J., Alvarado-Balderrama, L., Bauser, C. L., Becker, C., Birren, B. W., Chen, Z., Choi, J., Crouch, J. A., Duvick, J. P., Farman, M. L., Gan, P., Heiman, D., Henrissat, B., Howard, R. J., Kabbage, M., Koch, C., Kubo, Y., Law, A. D., Lebrun, M. H., Lee, Y. H., Miyara, I., Moore, N., Neumann, U., Panaccione, D. G., Panstruga, R., Place, M., Proctor, R. H., Prusky, D., Rech, G., Reinhardt, R., Rollins, J. A., Rounsley, S., Schard, C. L., Schwartz, D. C., Shenoy, N., Shirasu, K., Sikhakolli, U. R., Stüber, K., Sukno, S. A., Sweigard, J. A., Takano, Y., Takahara, H., Trail, F., van der Does, H. C., Voll, L. M., Will, I., Young, S., Zeng, Q., Zhang, J., Zhou, S., Dickman, M. B., SchulzeLefert, P., M.L. J., and Vaillancourt, L. J. 2012. Life-style transitions in plant pathogenic Colletotrichum fungi deciphered by genome and transcriptome analyses. Nat. Genet. 44:1060-1065

Oh, Y., Donofrio, N., Pan, H., Coughlan, S., Brown, D., Meng, S., Mitchell, T., and Dean, R. A. 2008. Transcriptome analysis reveals new insight into appressorium formation and function in the rice blast fungus Magnaporthe oryzae. Genome Biol. 9:R85.

Prusky, D., and Yakoby, N. 2003. Pathogenic fungi: Leading or led by ambient $\mathrm{pH}$ ? Mol. Plant Pathol. 4:509-516.

Prusky, D., McEvoy, J. L., Leverentz, B., and Conway, W. S. 2001. Local modulation of host $\mathrm{pH}$ by Colletotrichum species as a mechanism to increase virulence. Mol. Plant-Microbe Interact. 14:1105-1113.

Prusky, D., McEvoy, J. L., Saftner, R., Conway, W. S., and Jones, R. 2004. The relationship between host acidification and virulence of Penicillium spp. on apple and citrus fruit. Phytopathology 94:44-51.

Rohde, J. R., and Cardenas, M. E. 2004. Nutrient signaling through TOR kinases controls gene expression and cellular differentiation in fungi. Curr. Top. Microbiol. Immunol. 27:953-972.

Rollins, J. A., and Dickman, M. B. 2001. pH signaling in Sclerotinia sclerotiorum: Identification of pacC/RIM1 homolog. Appl. Environ. Microbiol. 67:75-81.

Shafran, H., Miyara, I., Eshed, R., Prusky, D., and Sherman, S. 2008. Development of new tools for studying gene function in fungi based on the Gateway system. Fungal Genet. Biol. 45:1147-1154.

Smith, D. G., Garcia-Pedrajas, M. D., Gold, S. E., and Perlin, M. H. 2003. Isolation and characterization from pathogenic fungi of genes encoding ammonium permeases and their roles in dimorphism. Mol. Microbiol. 50:259-275.

Soupene, E., He, L., Yan, D., and Kustu, S. 1998. Ammonia acquisition in enteric bacteria: Physiological role of the ammonium/methylammonium transport B (AmtB) protein. Proc. Natl. Acad. Sci. U.S.A. 95:7030-7034.

Soupene, E., Lee, H., and Kustu, S. 2002. Ammonium/methylammonium transport (Amt) proteins facilitate diffusion of $\mathrm{NH} 3$ bidirectionally. Proc. Natl. Acad. Sci. U.S.A. 99:3926-3931.

Stephenson, S. A., Green, J. R., Manners, J. M., and Maclean, D. J. 1997. Cloning and characterisation of glutamine synthetase from Colletotrichum gloeosporioides and demonstration of elevated expression during pathogenesis on Stylosanthes guianensis. Curr. Genet. 31:447-454.

Takano, Y., Kikuchi, T., Kubo, Y., Hamer, J. E., Mise, K., and Furusawa, I. 2000. The Colletotrichum lagenarium Map kinase gene CMK1 regulates diverse aspects of fungal pathogenesis. Mol. Plant-Microbe Interact. 13:374-383.

Taylor, S. S., Buechler, J. A., and Yonemoto, W. 1990. cAMP-dependent protein kinase: Framework for a diverse family of regulatory enzymes. Annu. Rev. Biochem. 59:971-1005.

Teichert, S., Rutherford, J. C., Wottawa, M., Heitman, J., and Tudzynski, B. 2008. Impact of ammonium permeases MepA, MepB, and MepC on nitrogen-regulated secondary metabolism in Fusarium fujikuroi. Eukaryot. Cell 2:187-201.

Tu, J. C. 1985. An improved Mathur's medium for growth, sporulation, and germination of spores of Colletotrichum lindemuthianum. Microbios 44:87-93.

van Nuland, A., Vandormael, P., Donaton, M., Alenquer, M., Lourenco, A., Quintino, E., Versele, M., and Thevelein, J. M. 2006. Ammonium permease-based sensing mechanism for rapid ammonium activation of the protein kinase A pathway in yeast. Mol. Microbiol. 59:1485-1505.

von Wiren, N., and Merrick, M. 2004. Regulation and function of ammonium carriers in bacteria, fungi and plants. Trends Curr. Genet. 9:95-120.

$\mathrm{Xu}$, J. R. 2000. MAP kinases in fungal pathogens. Fungal Genet. Biol. $31: 137-152$.

\section{AUTHOR-RECOMMENDED INTERNET RESOURCE}

National Center for Biotechnology Information Structure Group: www.ncbi.nlm.nih.gov/Structure 